\title{
The Effect of Colleagues' I-Deals on Performance: Based on the Social Learning Theory
}

\author{
Zheng Ren \\ Jinan University, Guangzhou, China \\ Email: 15116316731@163.com
}

How to cite this paper: Ren, Z. (2019) The Effect of Colleagues' I-Deals on Performance: Based on the Social Learning Theory. Open Journal of Social Sciences, 7, 335-346. https://doi.org/10.4236/jss.2019.712025

Received: December 8, 2019

Accepted: December 23, 2019

Published: December 26, 2019

Copyright $\odot 2019$ by author(s) and Scientific Research Publishing Inc. This work is licensed under the Creative Commons Attribution International License (CC BY 4.0).

http://creativecommons.org/licenses/by/4.0/

\begin{abstract}
As a new method and proposition of core talent management in human resource management, idiosyncratic deals have attracted the attention of scholars. However, there are different views on the influence of idiosyncratic deals in academic circles. Based on the social learning theory, this paper takes selfefficacy and proactive personality into the analysis framework to explore how the idiosyncratic deals of colleagues affect performance by affecting the selfefficacy at work. Our research samples are from employees in south China. Employees independently filled out information such as idiosyncratic deals of colleagues, work self-efficacy, work performance, proactive personality and demographic information. We received 256 valid questionnaires. Through analyzing the questionnaire survey, We reached the following conclusions: 1) colleagues' idiosyncratic deals positively influences work self-efficacy; 2) Work self-efficacy plays a complete intermediary role between colleagues' idiosyncratic deals and work performance. 3) Proactive personality plays a moderator role between colleagues' idiosyncratic deals and Work self-efficacy.
\end{abstract}

\section{Keywords}

Idiosyncratic Deals, Work Self-Efficacy, Proactive Personality, Performance

\section{Introduction}

Idiosyncratic deals (i-deals) are non-standardized work arrangements negotiated by employees and employers, which are different from other employees and benefit both employees and employers (Rousseau, 2001) [1]. Rousseau believes that idiosyncratic deals (i-deals) can be used to attract and manage core talent. He also believes that i-deals are about three parties: employees who have idio- 
syncratic deals (i-dealers), employers, and coworkers. The key to solving longstanding management dilemmas is three wins (Rousseau, 2001) [1]. In the existing studies, the positive effects of idiosyncratic deals are mostly discussed from employees and employers; for example, the relationship between idiosyncratic deals and organizational citizenship behavior (Anand, 2010) [2]; the curve relationship between flexible idiosyncratic deals and organizational support, turnover intention, and professional satisfaction (Chaudhry, 2011) [3]; the significant correlation between idiosyncratic deals and employee voice behavior $(\mathrm{Ng} \&$ Feldman, 2015) [4].

However, there is some debate about the impact of idiosyncratic deals. Some studies have analyzed the negative effects of idiosyncratic deals, for example, coworkers may think idiosyncratic deals are unfair and have negative consequences (Greenberg \& Colquitt, 2005) [5]. What some researchers have noticed is that the idiosyncratic deals of coworkers do not have a complete negative impact. Whether or not coworkers accept their coworkers' $\mathrm{i}$-deals depends on their relationship with the employees (i-dealers) and employers who have idiosyncratic deals. The balance between the value of the i-dealer and the value of the $\mathrm{i}$-deal is the factor that affects whether coworkers accept the i-deals (Martinko, Douglas, Ford \& Gundlach, 2004) [6]. Although the role of fairness in interpreting the reactions of coworkers has been repeatedly confirmed (Greenberg, 2005) [5], it has not been clearly tested, nor has it been tested for the subsequent behavioral responses of coworkers.

Therefore, the purpose of this paper is to explore the positive impact of coworkers' i-deals on employee performance from the perspective of social learning theory. In other words, from the perspective of alternative experience, coworkers' successful experience can enhance their work self-efficacy. Among them, proactive personality's positive response to pressure can also enhance this positive impact. To this end, this paper constructs the effect of colleague i-deals on performance, with work self-efficacy as the intermediary and proactive personality as the moderator model.

\section{Theory and Hypothesis}

\subsection{Idiosyncratic Deals and Performance}

Performance is often the goal of individual and organizational development. Although no research has shown that colleague i-deals have a significant impact on performance, according to the social learning theory, individuals form alternative experiences through observing others to influence themselves, such as high performance (Resick, 2013) [7] received i-deals colleagues usually belong to the high-level personnel who can produce high performance. Under the colleague's exemplary role, employee also can produce high performance. Therefore, we put forward:

H1a: Colleague's developmental i-deals are positively related to employee's performance. 
H1b: Colleague's flexible i-deals are positively related to employee's performance.

\subsection{The Mediating Role of Work Self-Efficacy}

In social learning theory, it is proposed that self-efficacy is an individual's judgment on whether he can successfully complete a certain behavior, and work selfefficacy is an individual's judgment on whether he can complete a certain work task (Rigotti et al., 2008) [8]. There are four factors that influence self-efficacy: alternative experience, existing experience, verbal persuasion, and physical and mental status (such as stress). Self-efficacy is the key intermediate state in the process of social learning. There are several ways in which colleagues' i-deals can enhance self-efficacy. Firstly, colleagues obtain i-deals and produce high performance (Rousseau, 2013; Parker, 2009; Tims et al., 2012) [9] [10] [11]. When employees see and observe the successful alternative experience, such vicarious experience will enhance their sense of self-efficacy. Secondly, for the employees who haven't got the i-deals at this stage, there will be some pressure of wanting but not getting. Moderate pressure will help to improve the sense of work self-efficacy, which is a kind of psychological arousal, which will increase work self-efficacy.

Social learning theory holds that people with a high sense of work self-efficacy tend to have a more positive attitude toward difficulties or tasks and exhibit superior behavioral efficiency, which often leads to better outcomes (Bandura, 1986) [12]. After observing colleagues receiving i-deals, employees improve their sense of work self-efficacy and work efficiency through substitution experience and physiological arousal, thus improving their work performance. A large number of studies have shown that work self-efficacy is a predictor of performance (Hannah, Schaubroeck, \& Peng, 2016; Carter, 2016; Frayne \& Geringer, 2000; Yuan, Weiser, \& Fischer, 2016; Yuan \& Weiser, 2016; Caprara et al. 2011; Weiser and Riggio 2010) [13]-[18].

In terms of empirical research, some scholars from the perspective of social learning have confirmed the mediating effect of self-efficacy between the influence of others, such as leadership style, and performance through the alternative experience of others (Mayer et al., 2009; Mitchell \& Palmer, 2010; Walumbwa et al., 2011) [19] [20] [21]. Therefore, we put forward:

H2a: Work self-efficacy plays a mediating role in the relationship between colleague's developmental i-deals and work performance.

H2b: Work self-efficacy plays a mediating role in the relationship between colleague's flexible i-deals and work performance.

\subsection{The Moderating Effect of Proactive Personality on Colleagues' I-Deals and Work Self-Efficacy}

Proactive personality refers to the stable tendency of individuals to take the initiative to affect the surrounding environment (Bateman \& Crant, 1993) [22]. 
Studies have shown that people with a high proactive personality respond positively to the environment and take action to achieve desired outcomes. Proactive personality has the potential to benefit individuals directly. More specifically, individuals with proactive personality may contribute to successful coping with career stress (Crant, 1993). When stressors have a clear source and are more cognitively inclined, a high level of proactive personality is beneficial (Harvey et al., 2006) [23].

Colleagues are given special work arrangements, which can be stressful for employees. For people with high levels of proactive personality, they will take the initiative to deal with this situation. In addition, clear sources of stress tend to be cognitive, so it is beneficial for employees with high proactive personalities to cope well with this situation. Therefore, for i-deals of colleagues, employees will have more sense of work self-efficacy to do their own work well, so as to change the situation. Through alternative learning, they can improve their work selfefficacy after observing colleagues get i-deals. Therefore, we put forward:

$\mathrm{H} 3 \mathrm{a}$ : Proactive personality plays a moderator role between colleagues' developmental i-deals and Work self-efficacy.

H3b: Proactive personality plays a moderator role between colleagues' flexible i-deals and Work self-efficacy.

\section{Method}

\subsection{Sample and Procedure}

This study collected data from employees in south China. With the help of the questionnaire star, employees independently filled in the status of colleagues' i-deals, work self-efficacy, work performance, proactive personality; finally obtained a total of 253 valid questionnaires. Among them, there were 108 males (42.69\%) and 145 females (57.21\%). Under age, 20 (1.98\%), 20 to 25 (50.2\%), 26 to $30(15.02 \%), 35(5.53 \%), 31$ - 36 to $402.77 \%, 41$ - 45 (7.51\%), 46 - 50 (5.14\%), 51 and $55(10.28 \%), 56(1.58 \%)$ education level above, for the most part for undergraduate $(61.66 \%)$, secondly, respectively is a specialist $(20.55 \%)$, a master's degree (11.07\%), middle school and the following (5.53\%), Dr. (1.19\%). Average working life is 2.05 years $(\mathrm{SD}=1.691)$ (Table 1$)$.

\subsection{Measures}

Colleague's i-deals. I-deals scale developed by Hornung et al. (2008) [24]. There are 12 items. All items were measured using a 5-point Likert scale of agreement with response options ranging from 1 strongly disagree to 5 strongly agree.

Work self-efficacy. Work self-efficacy scale developed by Chen (2001) [25]. There are 8 items. All items were measured using a 7-point Likert scale of agreement with response options ranging from 1 strongly disagree to 7 strongly agree.

Proactive personality. Proactive personality scale revised by Shang (2009) [26]. There are 11 items. All items were measured using a 7-point Likert scale of agreement with response options ranging from 1 strongly disagree to 7 strongly agree. 
Table 1. Distribution table of subjects' basic situation.

\begin{tabular}{|c|c|c|c|}
\hline Descriptor & Option & Quantity & Percentage \\
\hline \multirow{2}{*}{ Gender } & $\operatorname{man}$ & 108 & 42.7 \\
\hline & woman & 145 & 57.3 \\
\hline \multirow{9}{*}{ Age } & under 20 & 5 & 2.0 \\
\hline & $20-25$ & 127 & 50.2 \\
\hline & $26-30$ & 38 & 15.0 \\
\hline & $31-35$ & 14 & 5.5 \\
\hline & $36-40$ & 7 & 2.8 \\
\hline & $41-45$ & 19 & 7.5 \\
\hline & $46-50$ & 13 & 5.1 \\
\hline & $51-55$ & 26 & 10.3 \\
\hline & above 56 & 4 & 1.6 \\
\hline \multirow{5}{*}{ Education } & Middle school and the following & 14 & 5.5 \\
\hline & specialist & 52 & 20.6 \\
\hline & undergraduate & 156 & 61.7 \\
\hline & master & 28 & 11.1 \\
\hline & Dr. & 3 & 1.2 \\
\hline \multirow{7}{*}{ Work experience } & $1-5$ & 150 & 59.3 \\
\hline & $6-10$ & 45 & 17.8 \\
\hline & $11-15$ & 15 & 5.9 \\
\hline & $16-20$ & 9 & 3.6 \\
\hline & $21-25$ & 15 & 5.9 \\
\hline & $26-30$ & 10 & 4.0 \\
\hline & above 30 & 9 & 3.6 \\
\hline
\end{tabular}

Performance. Performance scale developed by Williams and Anderson (1991) [27]. There are 5 items. All items were measured using a 6-point Likert scale, from 1 (well below average) to 6 (well above average).

Control variables: gender, age, educational background and working years.

\subsection{Method}

SPSS21.0 and lisrel87 were used for statistical analysis of the collected data. Specific methods include descriptive statistical analysis, correlation analysis, reliability and validity analysis, confirmatory factor analysis, regression analysis, process macro for SPSS and so on.

\section{Result}

\subsection{Confirmatory Factor Analysis}

Confirmatory factor analysis was used to investigate the discriminant validity of 
work performance of self-efficacy, proactive personality, colleagues' developmental i-deals, colleagues' flexible i-deals, and performance. As shown in Table 2 , the fitting degree of the five-factor model was the best. RMSEA is 0.071 , CFI and NNFI are both higher than 0.90. As shown in the table, the fitting effect of the 5 -factor model is significantly better than that of the other 4 competing models, which indicates that the 5 variables have good discriminant validity and represent 5 different constructs.

\subsection{Descriptive Statistical Results}

In order to test whether the questionnaire structure obtained by exploratory factor analysis is ideal and to meet the needs of follow-up studies, this study continued to use questionnaire star and social software to distribute questionnaires to employees. In this study, a total of 250 online questionnaires were sent out, eliminated the questionnaire with wrong answers, consistent answers and obvious rules, and 222 valid questionnaires were received, with an effective recovery rate of $88.9 \%$. The mean, standard deviation and correlation coefficient of each variable are shown in Table 3. Both the colleague developmental i-deals and the colleague flexible i-deals are associated with the work self-efficacy

Table 2. Results of confirmatory factor analysis.

\begin{tabular}{lcccccc}
\hline \multicolumn{1}{c}{ Model } & $\chi^{2}$ & $d f$ & $\chi^{2} / d f$ & CFI & RMSEA & NNFI \\
\hline 1) Five-factor model: DI; FI; WSE; PP; JP & 893.44 & 395 & 2.26 & 0.97 & 0.071 & 0.97 \\
2) Four-factor model: DI + FI; WSE; PP; JP & 938.48 & 399 & 2.35 & 0.97 & 0.072 & 0.97 \\
3) Three-factor model: DI + FI; WSE + PP; JP & 1316.57 & 402 & 3.28 & 0.95 & 0.095 & 0.95 \\
4) Two-factor model: DI + FI; WSE + PP + JP & 1685.08 & 404 & 4.17 & 0.94 & 0.112 & 0.94 \\
5) One-factor model: DI + FI + WSE + PP + JP & 2873.99 & 405 & 7.10 & 0.90 & 0.156 & 0.89
\end{tabular}

Note. DI = Developmental I-deals; FI = Flexible I-deals; WSE = work self-efficacy; PP = Proactive personality; JP = Job performance.

Table 3. Variable means and bivariate correlations.

\begin{tabular}{|c|c|c|c|c|c|c|c|c|c|c|c|}
\hline & $M$ & $S D$ & 1 & 2 & 3 & 4 & 5 & 6 & 7 & 8 & 9 \\
\hline 1) Gender & 1.57 & 0.50 & 1 & & & & & & & & \\
\hline 2)Age & 3.61 & 2.24 & -0.06 & 1 & & & & & & & \\
\hline 3) Education & 2.82 & 0.74 & 0.03 & $-0.34^{* *}$ & 1 & & & & & & \\
\hline 4) Work experience & 2.05 & 1.69 & -0.05 & $0.74^{\star *}$ & -0.11 & 1 & & & & & \\
\hline 5) C's DI-deals & 3.38 & 1.11 & -0.05 & $0.29^{* *}$ & -0.01 & $0.26^{* *}$ & $(-0.88)$ & & & & \\
\hline 6) C's FI-deals & 3.17 & 1.11 & -0.07 & $0.31^{* *}$ & 0.01 & $0.28^{\star \star}$ & $0.74^{\star *}$ & $(-0.83)$ & & & \\
\hline 7) Proactive personality & 5.46 & 0.89 & 0.02 & $0.32^{* *}$ & $-0.13^{*}$ & $0.22^{\star *}$ & $0.32^{* *}$ & $0.33^{* *}$ & $(-0.88)$ & & \\
\hline 8) Work self-efficacy & 3.91 & 0.63 & -0.02 & $0.43^{* *}$ & -0.06 & $0.38^{\star *}$ & $0.33^{* *}$ & $0.35^{\star *}$ & $0.69^{\star *}$ & $(-0.89)$ & \\
\hline 9) Job performance & 4.38 & 0.85 & 0.07 & $0.29^{\star *}$ & -0.01 & $0.26^{\star *}$ & $0.27^{\star *}$ & $0.21^{\star *}$ & $0.54^{\star \star}$ & $0.66^{\star *}$ & $(-0.89)$ \\
\hline
\end{tabular}

Note. Gender: $1=$ men, $2=$ woman; Age: $1=$ under 20, $2=20-25,3=26-30,4=31-35,5=36-40,6=41-45,7=46-50,8=51-55,9=$ above 56; Education: $1=$ middle school and the following, $2=$ specialist, $3=$ undergraduate, $4=$ master, $5=\operatorname{Dr}$; ${ }^{*} \mathrm{p}<0.05,{ }^{*} \mathrm{p}<0.01$. Cronbach's alphas are provided in brackets. 
$(\mathrm{r}=0.33 .291, \mathrm{p}<0.01 ; \mathrm{R}=0.35 .291, \mathrm{p}<0.01)$, work performance $(\mathrm{r}=0.27 .291$, $\mathrm{p}<0.01 ; \mathrm{R}=0.21, \mathrm{p}<0.01)$. Job self-efficacy was positively correlated with job performance $(\mathrm{r}=0.661, \mathrm{p}<0.01)$.

\subsection{Regression Analyses}

In this study, hierarchical regression was used to test the results, as shown in model 6 and model 7 in Table 4, showing that there was significant positive correlation between the developmental and flexible i-deals of colleagues and job performance $(b=0.15, p<0.05 ; b=0.10, p<0.05)$. Hypothesis $1 \mathrm{a}$ and $1 \mathrm{~b}$ are supported.

Model 1 and model 2 showed that the regression coefficient between colleagues' developmental and flexible i-deals and work self-efficacy was significant $(b=0.12, p<0.05 ; b=0.13, p<0.05)$. Model 8 and model 9 showed that under the two i-deals, work self-efficacy $(b=0.97, p<0.05 ; b=0.901, p<0.05)$ had a significant regression coefficient with work performance. However, at this point, colleagues' developmental and flexible i-deals had a significant correlation with work performance $(b=0.05, p>0.05 ; b=-0.08, p>0.05)$. Hypothesis $2 a$ and $2 b$ get the support. Model 3 and 4, according to colleagues' developmental and flexible i-deals and proactive personality interaction $(b=0.06, \mathrm{p}<0.05)$ had a significant regression coefficient with work self-efficacy. Hypothesis $3 a$ gets the support. The colleagues' flexible i-deals and proactive personality interaction (b $=0.06, \mathrm{p}>0.05)$ hadn't a significant regression coefficient with work self-efficacy. Hypothesis $3 \mathrm{~b}$ did not get the support.

Simple slope analysis (Figure 1) found that when proactive personality was high, work self-efficacy increased with the increase of colleagues' developmental $\mathrm{i}$-deals $(\mathrm{b}=0.07, \mathrm{p}<0.05)$, and this positive relationship decreased when proactive personality was low $(b=-0.03, p>0.05)$.

According to bootstrapping analysis, as shown in Table 5, when proactive personality is higher than one standard deviation, the $95 \%$ confidence interval is $[0.0059,0.140]$, and 0 is not included in the confidence interval. The positive moderator of proactive personality is significant.

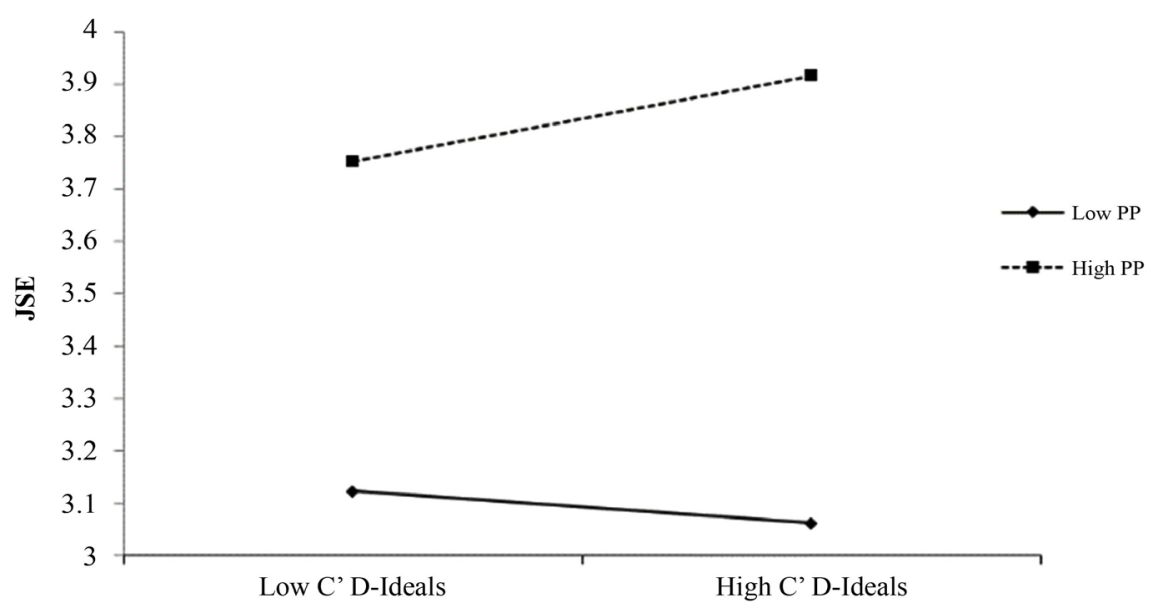

Figure 1. Moderator diagram of proactive personality. Note: JSE = Work self-efficacy; C' D-Ideals = colleagues' developmental i-deals; $\mathrm{PP}=$ proactive personality. 
Table 4. Regression analyses.

\begin{tabular}{|c|c|c|c|c|c|c|c|c|c|c|c|}
\hline \multirow{2}{*}{ Variable } & \multicolumn{5}{|c|}{ Work self-efficacy } & \multicolumn{6}{|c|}{ Job performance } \\
\hline & M1 & M2 & M3 & M4 & M5 & M6 & M7 & M8 & M9 & M10 & M11 \\
\hline Gender & 0.02 & 0.02 & -0.02 & -0.02 & 0.01 & 0.15 & 0.15 & 0.14 & 0.13 & 0.13 & 0.12 \\
\hline Age & 0.09 & 0.09 & 0.04 & 0.04 & 0.06 & 0.08 & 0.09 & 0.00 & 0.01 & 0.00 & 0.00 \\
\hline Education & 0.05 & 0.05 & 0.08 & 0.07 & 0.05 & 0.08 & 0.08 & 0.03 & 0.04 & 0.05 & 0.06 \\
\hline Work experience & 0.03 & 0.03 & 0.04 & 0.04 & 0.03 & 0.03 & 0.03 & 0.00 & 0.00 & 0.01 & 0.01 \\
\hline \multicolumn{12}{|l|}{ independent variable } \\
\hline C's DI-deals & $0.12^{*}$ & & -0.29 & & & $0.15^{*}$ & & 0.05 & & 0.12 & \\
\hline C's FI-deals & & $0.13^{*}$ & & -0.28 & & & $0.10^{*}$ & & -0.02 & & -0.15 \\
\hline \multicolumn{12}{|l|}{ Moderator } \\
\hline Proactive personality & & & $0.22^{*}$ & $0.24^{*}$ & & & & & & 0.21 & 0.10 \\
\hline \multicolumn{12}{|l|}{ interaction } \\
\hline C's DI-deals $\times$ Proactive personality & & & $0.06^{*}$ & & $0.04^{*}$ & & & & & -0.02 & \\
\hline C's FI-deals $\times$ Proactive personality & & & & 0.06 & & & & & & & 0.02 \\
\hline \multicolumn{12}{|l|}{ Mediating variable } \\
\hline Work self-efficacy & & & & & & & & $0.87^{\star}$ & $0.90^{*}$ & $0.74^{*}$ & $0.74^{*}$ \\
\hline $\mathrm{R}^{2}$ & 0.24 & 0.25 & 0.55 & 0.55 & 0.37 & 0.13 & 0.11 & 0.45 & 0.45 & 0.46 & 0.46 \\
\hline$\Delta \mathrm{R}^{2}$ & 0.23 & 0.23 & 0.54 & 0.54 & 0.35 & 0.12 & 0.10 & 0.43 & 0.43 & 0.44 & 0.44 \\
\hline $\mathrm{F}$ & $15.63^{\star}$ & $16.16^{*}$ & $42.79^{\star}$ & $42.85^{*}$ & $28.46^{*}$ & $7.60^{*}$ & $6.34^{*}$ & $33.20^{*}$ & $32.87^{\star}$ & $26.02^{*}$ & $26.07^{*}$ \\
\hline
\end{tabular}

Note. ${ }^{*} \mathrm{p}<0.05,{ }^{* *} \mathrm{p}<0.01$.

Table 5. Indirect effects and confidence intervals of bootstrapping at different levels.

\begin{tabular}{ccccc}
\hline $\begin{array}{c}\text { Different levels of } \\
\text { proactive personality }\end{array}$ & Effect & Standard error & Upper limit (95\%) & Floor level (95\%) \\
\hline-0.89 & -0.0247 & 0.0409 & -0.0963 & 0.0653 \\
0 & 0.0198 & 0.0270 & -0.0317 & 0.0747 \\
0.89 & 0.0643 & 0.0338 & 0.0059 & 0.140 \\
\hline
\end{tabular}

\section{Conclusions}

I-deals are an emerging work arrangement that affects both the i-dealers and their colleagues. Based on the theory of social learning, this paper analyzes that employees have obtained favorable results through alternative learning. Such alternative experience increases their sense of work self-efficacy, which is conducive to the increase of work performance. Employees with a high proactive personality, with a positive attitude, will be more active in dealing with the implicit pressure brought by colleagues' i-deals, and have a sense of work self-efficacy. Based on this, this paper constructs a model mediated by work self-efficacy and moderated by proactive personality, so as to make some theoretical and practical contributions to colleagues' i-deals. 


\subsection{Theoretical and Practical Significance}

Theoretically, firstly, previous researches on i-deals are mostly based on social exchange theory and social comparison theory. Based on the former, the positive correlation between i-deals and organizational commitment is studied (Christopher c. Rosen, 2013) [28]. Based on the latter, the relationship between i-deals and helping behavior is discussed (Guerrero, 2016) [29] and with the research from the perspective of colleagues on the fair theory, discusses the colleagues in the i-dealer changed the original input and output, will feel fair is broken (Rousseau, 2001) when employees feel colleagues' $i$-deals will increase their workload and reduce the may obtain ideal results, will influence the employee's job involvement (Greenberg et al. 2004). And based on social learning theory, this paper studied the employees by alternative experience increase self-efficacy, which further increases the performance, enriched the theoretical basis of research on i-deals again, this article embarks from the two kinds of i-deals, significant results only colleagues' developmental i-deals it may be that colleagues' developmental i-deals lease contract directly involved in promoting the development of individual resources and developmental i-deals compared with other types will produce greater productivity, because of its ability to directly improve employees ( Ng, 2017) [30], so employees will pay more attention to developmental i-deals. Finally, in the past, researches on i-deals from the perspective of colleagues have always focused on the negative aspects (Rousseau, 2001), while this paper explores employees' responses to i-deals from a positive perspective, enriching the field. In practice, first of all, enterprises should see the importance of alternative experience. After negotiating i-deals with some employees, they can publicize them in the organization. As long as employees meet the same requirements, they can also get i-deals. Secondly, when selecting talents, the organization should pay attention to the selection of employees with proactive personality, which is conducive to better improve the sense of work self-efficacy, thus increasing work performance.

In practice, first of all, enterprises should see the importance of alternative experience. After negotiating i-deals with employees, they can publicize them in the organization. As long as employees meet the same requirements, they can also get i-deals to encourage employees to actively develop their abilities. Secondly, when selecting talents, the organization should pay attention to the selection of employees with proactive personality, which is conducive to better improve the sense of work self-efficacy, thus increasing work performance

\subsection{Research Shortage and Envisage}

Although there are some innovative studies in this paper, there are still the following deficiencies and prospects: this study adopts horizontal data, and employees' work self-efficacy and work performance have certain timeliness, while the longitudinal study can draw more accurate and comprehensive conclusions. Therefore, the future research direction can consider the longitudinal study. In 
addition, this study only considered the regulating variable of proactive personality, and it is still unknown whether other aspects have an impact, as well as the direction and magnitude of the impact, which also needs to be studied.

\subsection{Summary}

This study focuses on the emerging construct of i-deals and explores its influencing mechanism. In order to better understand the impact of i-deals on colleagues of third parties, and put forward corresponding Suggestions. Through the questionnaire, the results showed that: 1) colleagues' idiosyncratic deals positively influences work self-efficacy; 2) Work self-efficacy plays a complete intermediary role between colleagues' idiosyncratic deals and work performance. 3) Proactive personality plays a moderator role between colleagues' developmental idiosyncratic deals and Work self-efficacy.

\section{Conflicts of Interest}

The author declares no conflicts of interest regarding the publication of this paper.

\section{References}

[1] Rousseau, D.M. (2001) The Idiosyncratic Deal: Flexibility versus Fairness? Organizational Dynamics, 29, 260-273. https://doi.org/10.1016/S0090-2616(01)00032-8

[2] Anand, S., Vidyarthi, P.R., Liden, R.C., et al. (2010) Good Citizens in Poor-Quality Relationships: Idiosyncratic Deals as a Substitute for Relationship Quality. Academy of Management Journal, 53, 970-988. https://doi.org/10.5465/amj.2010.54533176

[3] Vidyarthi, P.R., Chaudhry, A., Anand, S., et al. (2014) Flexibility Ideals: How Much Is Ideal? Journal of Managerial Psychology, 29, 246-265. https://doi.org/10.1108/JMP-07-2012-0225

[4] Ng, T.W.H. and Feldman, D.C. (2015) Idiosyncratic Deals and Voice Behavior. Journal of Management, 41, 893-928. https://doi.org/10.1177/0149206312457824

[5] Greenberg, J., Roberge, M.E., Ho, V.T., et al. (2005) Fairness in Idiosyncratic Work Arrangements: Justice as an I-Deal. In: Martocchio, J.J., Ed., Research in Personnel and Human Resources Management, Elsevier, Amsterdam, Vol. 23, 1-34. https://doi.org/10.1016/S0742-7301(04)23001-8

[6] Martinko, M.J., Douglas, S.C., Ford, R.C., et al. (2004) Dues Paying: A Theoretical Explication and Conceptual Model. Journal of Management, 30, 49-69. https://doi.org/10.1016/j.jm.2002.12.002

[7] Resick, C.J., Hargis, M.B., Shao, P., et al. (2013) Ethical Leadership, Moral Equity Judgments, and Discretionary Workplace Behavior. Human Relations, 66, 951-972. https://doi.org/10.1177/0018726713481633

[8] Rigotti, T., Schyns, B. and Mohr, G. (2008) A Short Version of the Occupational Self-Efficacy Scale: Structural and Construct Validity across Five Countries. Journal of Career Assessment, 16, 238-255. https://doi.org/10.1177/1069072707305763

[9] Hornung, S., Rousseau, D.M., Weigl, M., et al. (2013) Redesigning Work through Idiosyncratic Deals. European Journal of Work and Organizational Psychology, 23, 608-626. https://doi.org/10.1080/1359432X.2012.740171 
[10] Grant, A.M., Parker, S.K., Walsh, J., et al. (2009) 7 Redesigning Work Design Theories: The Rise of Relational and Proactive Perspectives. Academy of Management Annals, 3, 317-375. https://doi.org/10.5465/19416520903047327

[11] Tims, M., Bakker, A.B. and Derks, D. (2012) Development and Validation of the Job Crafting Scale. Journal of Vocational Behavior, 80, 173-186. https://doi.org/10.1016/j.jvb.2011.05.009

[12] Bandura, A. (1986) Social Foundations of Thought and Action: A Social Cognitive Theory. Journal of Applied Psychology, 12, 169. https://doi.org/10.2307/258004

[13] Hannah, S.T., Schaubroeck, J.M. and Peng, A.C. (2016) Transforming Followers' Value Internalization and Role Self-Efficacy: Dual Processes Promoting Performance and Peer Norm-Enforcement. Journal of Applied Psychology, 101, 252-266. https://doi.org/10.1037/apl0000038

[14] Carter, W.R., Nesbit, P.L., Badham, R.J., et al. (2016) The Effects of Employee Engagement and Self-Efficacy on Job Performance: A Longitudinal Field Study. The International Journal of Human Resource Management, 29, 2483-2502.

[15] Frayne, C.A. and Geringer, J.M. (2000) Self-Management Training for Improving Job Performance: A Field Experiment Involving Salespeople. Journal of Applied Psychology, 85, 361-372. https://doi.org/10.1037/0021-9010.85.3.361

[16] Yuan, S., Weiser, D.A. and Fischer, J.L. (2016) Self-Efficacy, Parent-Child Relationships, and Academic Performance: A Comparison of European American and Asian American College Students. Social Psychology of Education, 19, 261-280. https://doi.org/10.1007/s11218-015-9330-x

[17] Caprara, G.V., Vecchione, M., Alessandri, G., et al. (2011) The Contribution of Personality Traits and Self-Efficacy Beliefs to Academic Achievement: A Longitudinal Study. British Journal of Educational Psychology, 81, 78-96. https://doi.org/10.1348/2044-8279.002004

[18] Weiser, D.A. and Riggio, H.R. (2010) Family Background and Academic Achievement: Does Self-Efficacy Mediate Outcomes? Social Psychology of Education, 13, 367-383. https://doi.org/10.1007/s11218-010-9115-1

[19] Mayer, D.M., Kuenzi, M., Greenbaum, R., et al. (2009) How Low Does Ethical Leadership Flow? Test of a Trickle-Down Model. Organizational Behavior and Human Decision Processes, 108, 1-13. https://doi.org/10.1016/j.obhdp.2008.04.002

[20] Mitchell, M.S. and Palmer, N.F. (2010) The Managerial Relevance of Ethical Efficacy. In: Schminke, M., Ed., Managerial Ethics: Managing the Psychology of Morality, Routledge/Taylor \& Francis Group, Abingdon-on-Thames, 89-108.

[21] Walumbwa, F.O., Mayer, D.M., Wang, P., et al. (2011) Linking Ethical Leadership to Employee Performance: The Roles of Leader-Member Exchange, Self-Efficacy, and Organizational Identification. Organizational Behavior \& Human Decision Processes, 115, 204-213. https://doi.org/10.1016/j.obhdp.2010.11.002

[22] Bateman, T.S. and Crant, J.M. (1993) The Proactive Component of Organizational Behavior: A Measure and Correlates. Journal of Organizational Behavior, 14, 103-118. https://doi.org/10.1002/job.4030140202

[23] Harvey, S., Blouin, C. and Stout, D. (2006) Proactive Personality as a Moderator of Outcomes for Young Workers Experiencing Conflict at Work. Personality and Individual Differences, 40, 1063-1074. https://doi.org/10.1016/j.paid.2005.09.021

[24] Hornung, S., Rousseau, D.M. and Glaser, J. (2008) Creating Flexible Work Arrangements through Idiosyncratic Deals. Journal of Applied Psychology, 93, 655-664.

https://doi.org/10.1037/0021-9010.93.3.655 
[25] Chen, G., Casper, W.J. and Cortina, J.M. (2001) The Roles of Self-Efficacy and Task Complexity in the Relationships among Cognitive Ability, Conscientiousness, and Work-Related Performance: A Meta-Analytic Examination. Human Performance, 14, 209-230. https://doi.org/10.1207/S15327043HUP1403_1

[26] Shang, J.-Y. and Gan, Y.-Q. (2009) Effect of Proactive Personality on Career Decision-Making Self-Efficacy of College Graduates. Journal of Peking University (Natural Science Edition), 45, 548-554.

[27] Williams, L.J. (1991) Job Satisfaction and Organizational Commitment as Predictors of Organizational Citizenship and In-Role Behaviors. Journal of Management, 17, 601-617. https://doi.org/10.1177/014920639101700305

[28] Rosen, C.C., Slater, D.J., Chang, C.H., et al. (2013) Let's Make a Deal. Journal of Management, 39, 709-742. https://doi.org/10.1177/0149206310394865

[29] Guerrero, S. (2016) Idiosyncratic Deals and Helping Behavior: The Moderating Role of I-deal Opportunity for Co-Workers. Journal of Business and Psychology, 31, 433-443. https://doi.org/10.1007/s10869-015-9421-x

[30] Ng, T.W.H. (2017) Can Idiosyncratic Deals Promote Perceptions of Competitive Climate, Felt Ostracism, and Turnover? Journal of Vocational Behavior, 99, 118-131. https://doi.org/10.1016/j.jvb.2017.01.004 